\title{
Research on Community Games Space Planning and Design Strategies for Helping Children's Socialization
}

\author{
Jing Li \\ Art and Design College \\ Wuhan University of Science and Technology \\ Wuhan, China
}

\author{
Yifei $\mathrm{Li}$ \\ Art and Design College \\ Wuhan University of Science and Technology \\ Wuhan, China
}

\begin{abstract}
Under the background of rapid urban economic development, urban children's life is undergoing dramatic changes. The stratification of children's lives, partnership crisis, and social inadequacy has greatly affected the healthy development and growth of urban children. Rebuilding children's life centered on the community, subdividing children's life classes, rebuilding game groups, improving game content, promoting participation of families, schools, communities, and public interest organizations, and realizing the self-governance of children's communities are exploratory strategies based on community games space planning and design for helping children grow socially.
\end{abstract}

Keywords-game; children's life; community games space; children's socialization

\section{INTRODUCTION}

In 1992, the United Nations Children's Fund proposed the concept of a child-friendly city for the first time, arguing that the city should become an important place to protect children's rights and should provide children with a better space for development. Judging from the reality of most cities in China, the planning and construction of children's play places in urban open space are both insufficient in quantity and quality. Even though most residential areas have begun to attach importance to the establishment of game venues, they are still lacking in scientific and systematized planning, design, and construction. Most of constructions are simple in form, lacking in equipment and ideas. In particular, most of these venues rely on facilities and equipment to escape from children's lives (especially school-age children). Once the management and facilities are not adequately maintained, the site is abandoned, reflecting the reality that the planning and design of children's play areas is out of the essence of regional layout.

The living space is the container of life. Correspondingly, the vitality of the open space of the city comes from the collective space value of the place. The game place plan is to explain different kinds of contradictions and relationships of living, living group, living space put forward by the Japanese scholar Mr. Nakamura's in his article "The Theory of Planning and Design of Children's Playgrounds" based on social and economic contexts and natural conditions. The idea of these development directions also means the basic concept of regional planning and it is a sort of comprehensive planning and regional facilities layout; game site planning can be seen as a regional life version of the child in the geographical plan. It is the question of how the whole area plan can be used as playground.

\section{A. The Vicissitude of Children's Life}

After undergoing a period of rapid economic growth in the past 30 years, China's urbanization process has advanced by leaps and bounds, which has led to tremendous changes in children's lives. First, industrial mass production makes toys a mass consumer product, making networks and video games occupy children's spare time. Games that use natural objects in outdoor spaces are no longer so attractive to children, so, outdoor game content settings face enormous challenges. At the same time, the urban space price is becoming increasingly high, and children's outdoor game venues are crowded out, so that there are few game sites that can be easily accessed. In addition, the main places for children's education and care are transferred from families to public education institutions, which cause a reality that children's lives are institutionalized. Moreover, in order to win the fierce competition in the urban society, the children spend most of their spare time in training institutions, and the playing time is very little.

The more significant change lies in that the rapid development of the urban economy has brought about a rich and diverse life for modern children, and the originally of similar living structures based on the community suffer disintegration. If we are still following the pattern of planning before rapid development and make the community game sites of all classes stereotyped, we will inevitably departure from the structure of life.

\section{B. The "Partner Crisis" of Game Group}

The city is a stranger society. Social interactions tend to be more anonymous and defensive. Parents will restrict children's outdoor games for safety protection, which objectively reduce the game groups. Urban life pays more attention to economic status and interests, and the living space is different. Children who are familiar with school have to be separated after school because of their different places of residence. A social survey conducted among more than 1,000 primary school students in Nanjing shows: almost all children like to have companions to play with themselves; $43.7 \%$ of children often play with classmates and neighbors after school; $46.7 \%$ of children often play alone due to lack of playmates; only $9.7 \%$ of parents 
usually play with their children and even on the holidays, only $15.6 \%$ of parents can play with their children.

The game group is the premise of the game. The result of today's "partner crisis" is the weakening of children's playgroups, and rebuilding this group is crucial to reconstructing the community's game life.

\section{Insufficient Socialization of Children}

The lack of socialization of urban children has brought about many problems: children's lack of awareness of social behavior norms and social etiquette and interpersonal skills have been weakened; the formation of self-consciousness has suffered obstacles, missing the counterpoint of "me in the mirror" control; it is difficult to learn behaviors and responsibilities that are consistent with social roles in groups.

\section{ReCOnstructing ChILDREN'S LiFe CENTERED ON THE COMMUNITY}

With the great changes in children's lives mentioned above, the prominent problem in terms of game site planning is that community life, as an important function of traditional children's lives, is in decline and weakness. The consequences of this recession are unimaginable. The traditional lives of children in cities are distributed equally among families, communities, and schools .Family life is based on the relationship between parents and children while school life is based on the relationship between teachers and children. Only the core of community lies in the relationship among children. The essence of this kind of relationship establishment is the spontaneous self-governance phenomenon of children in the community. This function of the community cannot be replaced by the other two kinds of living space. It gives an important generator of children's personality growth and socialization.

The explanation of "socialization" in the psychological dictionary is: individuals acquire knowledge, language, rules of social behavior, values, and communication skills, so that they can integrate with the society, and they can act freely in a socially acceptable way, moving from one individual to a qualified society member. $\mathrm{Hu}$ Quanzhu and $\mathrm{Ge}$ Beibei summed up in the "sociological interpretation of children's Games": the game is a non-productive, non-consumer social interaction system with self-pleasure as its internal purpose. Chinese scholar Ma Hemin believes that individual socialization is the internalization of knowledge, skills, values, and behavior norms required by society in the process of socialized subjects and objects' interaction, forming certain behavioral patterns and personality characteristics to adapt and transform society, and develop your own process. Children's socialization is the process of children's personality and sociality interaction and development. It can be achieved by a socialized mechanism, and the game is the most favorable realization mechanism.

The children's game itself is a social interaction system that creates practical conditions for children to grow from natural person to social person. In the game, children achieve social interaction through three main ways: social structure mapping, normative cognition and role play. For the social mechanism of game simulation, its mapping includes different social structures such as competition and cooperation. In addition, a society of game can be established. Reconstructing the children's life centered on the community is an important means to realize that take game as a social mechanism.

\section{A. A. Delegated Hierarchy Separation That Corresponds to Diverse Life}

In order to reconstruct children's lives, we must first face the stratification of children's lives, and guide the stratification of children's lives by diversifying their lives. This division is not simply based on children's age, gender and other indicators, but should be more specific. Take school-age children as an example. The first type is centered on home-based study tuition, supplemented by schools, and lack of community life. These children live at two points and one line and lack of outdoor activities. So, in general, their physical fitness tends to be poor and partners are limited to schoolmates. In consequence, they have the shortest game time. In the second category, their game activities often take place in schools. Even after school, students still participate in clubs or spontaneous games. And their community life is less. This type of children's communities and schools are often in one jurisdiction. Their community life is placed by school life. However, due to campus management, activity content, and venue restrictions, the game needs cannot be fully met. The third type of children is indifferent to school learning and collective activities. Their family management is loose and they often wander in the community. Such children lack family and self-management. Even though they often appear in the community and their activities are often lack of organization and correct guidance. Their growth is very vulnerable to bad social ethos. Targeted increasing children's outdoor physical activity, greater freedom of game settings, and strengthening the campus and community's organization and deployment of children's activities are all effective ways. Those who are loitering in the community are naturally influenced and positively guided by active group activities.

\section{B. Rebuild Community Game Groups}

The game community is the premise of the game. The life of community groups can simulate the real society, help children understand the rules, learn to abide by rules, and form a complete sense of self-recognition and social order. The greatest value of community life for children is that it is an autonomous society. This kind of independent life gives the children the greatest social experience. The reconstruction of game groups cannot be realized naturally like the previous living conditions and it must rely on the assistance of schools and families. Schools and parents do not have to intervene too much in their children's lives. They only need to do their best to achieve and maintain this autonomous state and protect game activities from being disturbed. In addition, community managers should actively take part in and attract children's education professional social welfare organizations to participate in co-construction.

With the rapid development of information networks, the reconstruction of game groups can be carried out through online and offline integration, so that the simple physical space 
game can be combined with virtual online organization activities to fully cover children's lives and ensure that their settings can effectively enrich and extend the use of community gaming venues.

\section{Game Content Quality Improvement}

The appeal of the game comes from the setting of the activity content, which includes that what kind of skills the individual uses, what rules they follow, and how they occur in the group, gaining a state experience like competition, collaboration, and confrontation. The basic guarantee of this setup is to provide activities that can be "repeatedly practiced." It enables individuals and groups to have a close connection with each other. For example, there are some traditional venue games such as "Paying Western Painting", "Hopping", Throwing Sandbags" and so on. The "repeated practice" activities enable individuals to exercise well in physical fitness, athletic skills, fine activities, observation and creativity, experience and exploration, and willpower. When it is linked with group activities, the games' function of social structure simulation, rules compliance, role playing and other functions are naturally highlighted. As early as 1943, Danish designer Sorensen designed the first adventure game venue in Copenhagen. He used fence to build a certain site, which contains various building materials and waste industrial equipment. The children can use these materials autonomously to build a new field. Moreover, there are specialized professional adults to lead activities, such as the construction of houses, walls, planting, digging, small animal husbandry etc. In this process, the so-called "repeated practice" activity is actually an individual construction skill, and the final result must be realized relying on social division of labor within the game group and organization management.

The goal of improving the game content should include energy release, risk-taking and exploration, closeness to nature, promotion of group cooperation, establishment of friendships, and simulation of social structure.

\section{Strengthen the Regional Cultural Spirit}

It's necessary to put children's life in the context of the community and the cultural life of the city so that the value and significance of the activities of the games are extended. Children live in a specific cultural context. From the time of their birth, their physical, psychological, social development characteristics, personality characteristics, etc. are naturally affected by the cultural features of their own region. Cultural identity has the function of predetermining the social role of a person. It provides the direction of value norms and the support of sociality as a social person to determine the position of people in cultural groups and society. There is a special relationship between cultural identity and children's socialization. Cultural identity can be internalized into human values, social cognition, social emotions, and attitudes. It can also be externalized into human behaviors, behaviors, rules, and social skills.

In the past two years, community gardens have become a hot topic in community life. In fact, in the United States, in many large cities, hundreds of community gardens have begun to bloom. They are located in the streets, parks, schools, and rooftops of cities. Residents can not only compost their vegetables in community gardens, but more importantly, it is a paradise for children. In China, a natural education-oriented social organization called "humble cottage of four leaf clovers", guides the public green units or agencies in Shanghai city to build more than 20 distinctive community gardens, to keep green in an urban environment and create a rich natural environment so that they can bring more people to live a green life. One of them is the Garden of Chuangzhi Farm, where the fertilizer is the dog's poo, the leaves and the weeds. The collected rainwater is used to water the plants and the roads in the garden are paved with small stones, making the road have rustic charm and absorb water well like sponges. The citizens bring their children to Chuangzhi Farm to learn how to grow vegetables, identify grains, pick fruits and vegetables, collect seeds, and enjoy the pastoral times. They also learn to use a perpetual cycle to maintain green and ecological balance and to be close to nature and land. Although such community gardens are mainly aimed at public participation and community building, health, environmental protection, and happy community culture have penetrated into every corner of the community and enriched children's lives in the community. This has undoubtedly provided positive and helpful inspiration guidance for the planning and design of community game places.

\section{SugGeStions FOR COMMUNITY GAMING Site DESIGN}

Community game venues should provide more venues that can safely carry out large-scale muscle group exercises so that children are allowed to run and jump without any scruples and improve their physical fitness; at the same time, the venue should take into account the fine dexterity of the hand and offer people opportunity to be able to operate different elements.

Independent natural areas should be provided. It's necessary to supply the natural materials that can be used to facilitate outdoor construction, and meanwhile, it should be helpful for the observation of changes in the natural climate conveniently to protect insects, birds and small animals.

While setting up activities venues for large group, it is also advisable to have suitable venues for small groups and to set more breaks and observation points to meet children with different personality and communication skills. Fixed facilities, not only refers to the game equipment, but also can be a small meteorological observation station. In addition, it is also important to ensure the good maintenance and management of the site.

The construction of game venues should be closely integrated with the construction of communities and set up long-term community activities involving communities, families, and public education institutions. Based on the children's interests and hobbies, special education programs can be developed. At the same time, the site design must ensure that the adult exerts minimal control and guarantees children's autonomy, freedom of entry and exit. It's wise to stablish links with the activities of the campus and infant care institutions to form a sense of identity among small groups, and it is also vital to maintain the inner continuity of different 
living spaces. The integration of urban healthy lifestyles can be achieved through gardening, animal husbandry, wooden workshops, and community bazaars.

\section{CONCLUSION AND REFLECTION}

The development of modern cities is vigorous and the footsteps of building a good city for children can not be stopped. Even though the virtual Internet world takes up more time and energy for children, the children's playing space with community orientation is irreplaceable for children's personality growth and socialization.

Relevant organizations should pay attention to the changes in children's lives and take appropriate measures in a timely manner in order to better rebuild the game community and enhance the game content. Families, schools, communities, and public welfare organizations should actively participate in the efforts to realize the self-government of children's communities, so that community game places are no longer closed, single venues, but vital spaces that value children's lives and face city life, and ultimately help urban children to achieve sociality development.

\section{REFERENCES}

[1] Nakamura, Xin Geng, Ruofei Gao. Planning and Designing Theory of Children's Playgrounds,Landscape and Architecture[J], 2012 (3) :142147

[2] Yujuan Pan. The Impact of Urbanization on Children: A Research Perspective Based on Children's Game Changes, Jianghan Forum[J], 2011 (11) : 137-140

[3] Quanzhu $\mathrm{Hu}$, Beibei Ge. Sociological Interpretation of Children's Games, Journal of Sports and Science, 2011,32（5）: 15-18

[4] Claire.Cooper. Marcus, Caroline. Francis writes,Jiankong Yu,Peng Sun,Zhifang Wang translate. Place of Human Nature - Guidelines for Urban Open Space Design, Beijing:China Architecture \& Building Press, 2017.2

[5] http://www.envir.gov.cn/info/2017/7/76130.htm 